\title{
CONSUMINDO COMO UMA GAROTA: SUBJETIVAÇÃO E EMPODERAMENTO NA PUBLICIDADE VOLTADA PARA MULHERES ${ }^{1}$
}

\author{
Cynthia Hamlin
} é Professora do Departamento de Sociologia da Universidade Federal de Pernambuco. Recife, PE, Brasil.

E-mail:<cynthiahamlin@hotmail.com>

\section{Gabriel Peters}

é Professor do Departamento de Sociologia da Universidade Federal de Pernambuco. Recife, PE, Brasil.

E-mail:<gabrielpeters@hotmail.com>

http://dx.doi.org/10.1590/0102-167202/103

\section{Introdução}

Os estudos sobre consumo constituem um campo privilegiado para pensar a relação entre cultura e subjetividade. Com a chamada "virada cultural", esses estudos reforçaram os aspectos comunicativos, expressivos e, mais recentemente, subjetivantes do consumo. Embora autores como Veblen (1987 [1899]) já houvessem alertado para a dimensão simbólica do consumo conspícuo ou ostentatório entre as classes abastadas do século XIX, no "capitalismo tardio" o consumo e seu principal veículo, a publicidade, têm assumido um papel sem precedentes na mediação de identidades, poderes e mesmo direitos. Ao atrelar determinados

\footnotetext{
1 Uma versão resumida deste trabalho foi apresentada no GT de Sociologia da Cultura do $18^{\circ}$ Congresso Brasileiro de Sociologia, em julho de 2017, e deverá constar de seus anais. Agradecemos aos professores Edson Farias e Maria Celeste Mira pela oportunidade. Também agradecemos a Maria Eduarda Rocha, Gabriel Cohn, Frédéric Vandenberghe e aos membros do Grupo de Estudos em Teoria Social e Subjetividades (GETSS) do Programa de Pós-Graduação em Sociologia da Universidade Federal de Pernambuco (PPGS-UFPE) pelas valiosas críticas e sugestões ao texto, em particular: Aloízio Barbosa, Amarildo Malvezzi, Dayra Batista, Fernanda Fonseca, Mariana Pimentel, Rodrigo Mota, Suzy Luna e Thiago Panica.
} 
bens e serviços a estilos de vida e formas de identidade, a propaganda parece apostar em muito mais do que na formação de consumidores pela criação e satisfação de necessidades: o que está em jogo é uma concepção de consumo tanto como expressão de uma subjetividade quanto - mais radicalmente - como uma via para a sua construção.

Essa questão se coloca de forma particularmente evidente no chamado femvertising (numa tradução literal, "publicidade fem"): um tipo de publicidade baseado em uma proposta de emancipação feminina concebida como "empoderamento". Parte do problema é que "empoderamento" consiste em um termo altamente polissêmico: ora definido como autocontrole e autoconstrução, ora em termos de influência social, poder político ou direitos sociais, o conceito vem sendo indistintamente aplicado aos níveis individual, organizacional e societal, com pouca ou nenhuma atenção às relações de continuidade e de ruptura entre agência individual, ação coletiva e transfor168 mação estrutural (Aranha, 2014; Sardenberg, 2008).

De uma perspectiva do mercado, contudo, o femvertising tem se mostrado estratégia eficiente. Uma enquete sobre o fenômeno, realizada com 628 mulheres pela revista SheKnows, revelou que: $92 \%$ das respondentes se lembravam de pelo menos uma marca "pró-mulheres"; $52 \%$ comprou um produto porque gostou da forma como as mulheres eram representadas nos seus anúncios; e $46 \%$ seguiu uma marca em mídias sociais devido à mensagem de empoderamento por ela veiculada (Stampler, 2014).

Um dos mais bem-sucedidos exemplos desse fenômeno é uma "campanha pelo empoderamento de meninas" que, desde 2014, vem ganhando notoriedade ao tentar promover o aumento da autoconfiança entre adolescentes. Cerne de uma campanha publicitária dos absorventes Always, da Procter \& Gamble, o vídeo "Como uma garota" (Like a girl), produzido pela documentarista canadense Lauren Greenfield para a agência Leo Burnett, ganhou 
diversos prêmios importantes da área, incluindo o Grand Prix e o Glass Lions (categoria para promover a igualdade de gênero) do prestigioso Cannes Lions, o Festival Internacional de Criatividade. Mas é a difusão nas mídias digitais que nos dá a real dimensão de seu alcance. De acordo com dados apresentados no Festival, até junho de 2015, a hashtag "like a girl" havia obtido 4,58 bilhões de reações no mundo inteiro ${ }^{2}$. Até a redação deste texto, o vídeo da propaganda alcançara quase 100 milhões de visualizações apenas no canal oficial da marca no Youtube. Juntamente com a campanha dos produtos da Dove "pela beleza real", lançada em 2004, enfatizando a autoestima feminina, a campanha da Always vem sendo considerada um dos marcos do femvertising. Como veremos, o discurso veiculado nessa propaganda possui, se não alusões implícitas, pelo menos ressonâncias notáveis com reflexões acadêmicas influentes no feminismo da segunda onda, como os estudos da filósofa Iris Marion Young (2005 [1980]) sobre o "lançar como uma garota" e os da psicóloga Carol Gilligan (1993 [1982]) sobre o desenvolvimento moral infantil, marcado por um decréscimo da autoconfiança na passagem da infância à adolescência entre meninas.

Na forma de slogans ou de documentários curtos em que a mensagem de empoderamento assume o primeiro plano em relação ao próprio produto ${ }^{3}$, esse tipo de campanha ilustra uma estratégia publicitária descrita por Maria Eduarda Rocha (2009) em seu trabalho sobre "a nova retórica do capital”, narrativas que legitimam certas concepções de "vida plena" associadas ao grande capital no período

\footnotetext{
2 "CASSIES Grand Prix: Always strikes a chord". Disponível em: $<$ http:/ / strategyonline.ca/2016/02/12/cassies-grand-prix-always-strikes-a-chord/>. Acesso em: 23 fev. 2018.

3 Não há, por exemplo, qualquer menção a absorventes na propaganda da Always; "não é só cacho, não é só cor, é mais poder", limita-se a afirmar a publicidade de uma linha de tintura para cabelos da Garnier Nutrisse.
} 
neoliberal. Na publicidade essas narrativas são estruturadas a partir de "conceitos" que traduzem determinados valores, identificados por meio de pesquisas de mercado, na forma de "uma ideia básica sobre a qual assenta a relevância do produto ou serviço na vida do consumidor" (Rocha, 2009, p. 24). Em sua excelente análise da publicidade brasileira contemporânea, a autora identificou os conceitos de "qualidade de vida" e "responsabilidade social" como cernes da concepção de vida plena mobilizada na passagem do desenvolvimentismo para o neoliberalismo no final da década de 1980. No caso do femvertising, o empoderamento feminino é explicitamente apresentado como o valor fundamental em torno do qual a imagem do produto ou da marca se estrutura.

De Jameson (1991) a Boltanski e Chiapello (2007), diversos autores já notaram que o capitalismo das últimas décadas exibe uma imensa capacidade de apropriar à sua

170 própria lógica manifestações ideológicas que lhe são estranhas ou mesmo francamente opostas. O percurso no qual o conceito de empoderamento feminino passa de uma acepção francamente "coletivista" a uma versão individualizada pode ser situado naquela dinâmica mais ampla do capitalismo tardio. A questão principal colocada para nós neste artigo é: que sentidos o conceito de empoderamento pôde assumir a fim de possibilitar a articulação de valores tão díspares - como a emancipação feminina com vistas à construção de um mundo mais justo, igualitário e livre, de um lado, e as novas formas de distinção, opressão e subordinação associadas ao capitalismo global, flexível ou neoliberal, de outro?

\section{0 "feminismo da mercadoria": 0 estranho casamento entre feminismo e publicidade}

A relação entre feminismo e publicidade não é nova. Como argumenta Pauline Maclaran (2015, todas as ondas do feminismo tiveram algum tipo de relação com o mercado 
e com a publicidade 4 . Partindo de uma crítica ao que hoje denominamos "cultura de consumo", foi o romancista Émile Zola, em O paraíso das damas (2008 [1883]), quem primeiro atentou para as lojas de departamento como um espaço por onde as mulheres de meados do século XIX podiam circular livremente, sem a companhia de um homem. Não por acaso, muitas mulheres do movimento sufragista inglês se reuniam em lojas de departamento como a Selfridges, cujo dono, Gordon Selfridge, apoiava o movimento. Nesse contexto a publicidade era frequentemente percebida pelo movimento sufragista do final do século XIX e início do XX como algo positivo para a visibilidade de suas campanhas (Maclaran, 2015).

As relações entre feminismo e publicidade foram mais contenciosas entre os anos 1960 e 1980, período que caracteriza a segunda onda do movimento. Para além de suas diferenças, feministas liberais, como Betty Friedan, e feministas radicais, como Germaine Greer, criticaram fortemente as ideologias que manipulavam os desejos e os corpos das mulheres, de forma a confiná-las à esfera doméstica. Reforçadas pelas representações da mulher na publicidade em termos estereotípicos e negativos, tais ideologias enfatizavam os papeis de mãe e de esposa e infundiam nessas mulheres desejos, demandas e normas culturais que, na visão de feministas marxistas, estimulavam o ciclo de consumo do capitalismo (Maclaran, 2015; Eichner, 2016). Desde então a crítica feminista à representação das mulheres em termos objetificantes na mídia e na cultura pop tem sido mobilizada por uma infinidade de agentes culturais (Zeisler, 2016). É justamente essa mobilização que dá origem ao que se

\footnotetext{
${ }^{4}$ Dado que nosso propósito não é fornecer um sistema classificatório relativo às três ondas do feminismo, mas meramente ilustrar as relações gerais entre feminismo e publicidade, nossa caracterização das três ondas inevitavelmente apresenta simplificações que desconsideram as nuances internas a cada uma delas. Isso, contudo, não deve obscurecer o fato de que alguns temas e questões centrais relativos a cada onda condicionaram a forma como a relação entre feminismo e publicidade tornou-se possível.
} 
conhece por "feminismo da mercadoria", conceito crítico, fruto da virada cultural nas ciências sociais e nas humanidades que, em larga medida, inspirou as teorias de terceira onda do feminismo.

Em alusão à noção de "fetichismo da mercadoria" cunhada por Marx, a ideia de "feminismo da mercadoria" designa os modos pelos quais propostas e símbolos feministas são apropriados por interesses comerciais. A propaganda aparece aqui como a principal instância dessa instrumentalização mercadológica (Gill, 2008, p. 583). A primeira formulação detalhada do conceito aparece no livro de Robert Goldman, Reading ads socially (1992, p. 132-156). Concentrando-se na indústria cultural estadunidense, Goldman observou que, por volta da segunda metade dos anos 1980, as campanhas publicitárias nos EUA foram pressionadas a se reinventar em resposta a três desafios: a) "a fadiga do signo”, isto é, a de-sensibilização da receptividade 172 dos consumidores em face da overdose diária de informações e imagens publicitárias na cultura de consumo "pós-moderna"; b) o crescimento de uma audiência cética, cuja experiência no trato com as mídias levava a suspeitar dos estratagemas da publicidade para fazê-la consumir; e c) a reação hostil de um alto contingente de mulheres à estereotipificação sexualizante da feminilidade que era traço recorrente nas campanhas publicitárias.

O último fenômeno refletia justamente o impacto das críticas que o feminismo da segunda onda vinha, há muito, dirigindo à transformação da mulher em objeto de consumo visual na publicidade. A força dessa crítica ideológica era incrementada por um fator de cunho econômico: a crescente autonomia financeira das mulheres, resultado da maciça entrada feminina no mercado de trabalho que marcara as décadas anteriores (Castells, 1999, pp. 179-286). Para além do impacto ético-político da crítica feminista, os veículos de publicidade tinham uma razão puramente 
estratégica para modificar o feitio de suas mensagens: "mostrar uma mulher deitada em... um carro", por exemplo, não é a melhor estratégia "se o objetivo é vender tal carro para mulheres” (Gill, 2008, p. 583). Segundo Goldman (1992), o feminismo da mercadoria foi a resposta engenhosa da publicidade à nova conjuntura: introduzir temáticas feministas nas mensagens publicitárias pela via estetizante típica da propaganda, na qual os produtos anunciados são vinculados a signos expressivos de liberdade, independência e autonomia, valores centrais daquilo a que David Harvey (2005) se refere como a dimensão ética do neoliberalismo.

Portanto, a ideia de feminismo de mercadoria serve como um contrabalanço crítico às visões que sustentam, sem maiores ressalvas, que a publicidade contemporânea estaria se "tornando" feminista ou "refletindo" o impacto do feminismo na sociedade. O influxo marxista da noção aponta para o que Fredric Jameson (1991, p. 18) caracterizou como a capacidade "canibalizadora" do "capitalismo tardio", isto é, sua habilidade de explorar comercialmente as próprias manifestações ideológicas de resistência a ele (por exemplo, a imagem de Che Guevara, o anarquismo do movimento punk, os best-sellers de Slavoj Žižek).

A ideia do "feminismo publicitário" também pode ser criticada, no entanto, a partir de preocupações "interiores" ao movimento feminista. Gill (2008, p. 584) nota, por exemplo, que uma das principais estratégias semióticas do feminismo da mercadoria consiste em articular os "novos signos feministas" de sucesso e autonomia (o carro, a pasta e o tailleur da alta executiva) aos "velhos signos de feminilidade" (maquiagem, cabelos longos e outros traços da atratividade feminina convencional). Ao sugerir que não haveria qualquer tensão entre ser profissionalmente realizada e ser atraente para os homens, a publicidade constrói a ideia da "super-mulher: poderosa, respeitada, bem-sucedida, assim como, sem esforço, linda e atraente (e, em alguns casos, 
também uma mãe perfeita)" (Gill, 2008, p. 584). Tais estratégias caracterizam uma dimensão central dos discursos midiáticos contemporâneos em torno das mulheres: a mistura de ideias feministas e antifeministas na produção de subjetividades gendradas (Gill e Scharff, 2011).

Nesse sentido, em que pese a crítica à noção não nuançada de que a publicidade contemporânea estaria simplesmente se tornando feminista, também é necessário rejeitar a ideia de que ela esteja completamente dissociada do próprio feminismo. De modo correlato, uma análise crítica da publicidade pode reconhecer seus ardis ideológicos sem supor que eles neutralizem quaisquer efeitos "progressistas" ou "emancipatórios" de suas mensagens (p. ex., o despertar do interesse sobre temáticas feministas em parte da audiência). No que toca a este como a outros temas da teoria social crítica, é recomendável a manutenção de uma sensibilidade ambivalente, isto é, simultaneamente consciente de 174 estruturas de dominação e de alternativas de emancipação (Vandenberghe, 2009, p. 290). Essa recomendação nos parece particularmente útil para tratar das relações entre a publicidade e o feminismo de terceira onda.

Grandemente influenciada pela virada cultural na década de 1990, a terceira onda do feminismo reconheceu o impacto mútuo de diferentes sistemas de opressão - como classe, raça, gênero, etnicidade e sexualidade -, mas também celebrou as diferenças com base no reconhecimento da fluidez e instabilidade das categorias identitárias. De modo explícito ou implícito, a dominação cultural tendeu a ser considerada um fator mais importante na produção de injustiças do que a exploração de classe, com a luta política por reconhecimento da própria identidade/ diferença ganhando primazia sobre a redistribuição econômica (Fraser, 1995). De uma perspectiva teórica e política, portanto, a guinada cultural nos estudos feministas diz respeito àquilo a que Michèle Barret (1992, p. 215) se referiu 
em termos de uma "virada paradigmática" que deslocou as antigas preocupações com a estrutura social, as desigualdades materiais e a opressão, em favor de questões relativas a "sexualidade, subjetividade e textualidade".

Para autores como Jameson (1991), se vista de uma perspectiva histórica, a virada cultural refere-se ao fato de que, nas sociedades do capitalismo tardio ou "pós-modernas", a esfera da cultura tornou-se coextensiva à sociedade de mercado, em um processo de "culturalização da economia" - ou, o que vem a dar no mesmo para o autor, "mercadorização da cultura" - que abarca até as esferas mais recônditas da vida cotidiana: compras, atividades profissionais, lazer, publicidade, espaço doméstico, sonhos, imaginação, fantasias. E nada teria sido tão benéfico ao capitalismo tardio quanto a celebração das diferenças que a virada cultural trouxe consigo: as identidades passaram a ser vendidas e compradas em um mercado que promovia uma infinidade de estilos de vida, dentre os quais se inclui o empoderamento feminino. À medida que a rebeldia do movimento foi sendo cooptada pelo mercado, o feminismo (particularmente o ambíguo "pós-feminismo") tornou-se palavra de ordem na cultura popular, aparentemente relegando questões de desigualdade e injustiça a um passado distante (Maclaran, 2015).

Foi assim que na última década, nos termos de Andi Zeisler (2016), o feminismo, ao menos em sua versão pop, tornou-se cool. De algo que não ousava dizer seu nome fora de certos círculos, o feminismo passou a uma espécie de identidade mainstream, iconoclasta, divertida e, sobretudo, acessível a qualquer um pela via do consumo. Consumir é empoderar-se e, a crermos na publicidade dirigida a mulheres, o empoderamento feminino tornou-se tão ubíquo a ponto de a entrevista fictícia publicada pela revista satírica The Onion (Women now empowered..., 2003) nos fornecer um retrato fiel de parte significativa do imaginário popular: 
“[...] Do que ela come no café da manhã à forma como ela limpa sua casa, a mulher atual vive em um estado de empoderamento quase constante", disse Barbara Klein, professora de estudos de mulheres no Oberlin College [...] "Há apenas 15 anos, uma mulher só poderia se sentir empoderada ao ter sucesso em um mundo do trabalho dominado por homens, ao afirmar seus próprios desejos e necessidades sexuais, ou ao forçar uma voz mais forte na política”... [A] compra de roupas, antes considerada uma ação mundana de poucas implicações sociopolíticas, é agora uma declaração feminista ousada... "Possuir e usar dúzias de pares de sapatos é uma maneira de uma mulher anunciar que é forte e independente, e que ela pode se calçar sem ajuda de um homem. Ela está dizendo, 'cuidado, mundo dominado por homens, aqui venho eu e meus sapatos'”.

Mas será que é só isso? A própria mudança nas repre176 sentações femininas, fruto da denúncia das feministas de segunda onda, não apontaria para a possibilidade de formas distintas de subjetivação de meninas e mulheres? Há nesse processo algum tipo de "empoderamento" em curso? Já mencionamos que o conceito de "empoderamento" é tremendamente polissêmico. A análise de suas mutações ao longo das últimas quatro ou cinco décadas revela, no entanto, uma nítida tendência semântico-ideológica: a passagem de um sentido associado a uma pauta coletivista de transformação política para uma acepção crescentemente individualizada, associada a ideais de realização, sucesso e autonomia pessoal conformes à dinâmica do capitalismo neoliberal. É desse processo que nos ocuparemos agora.

\section{0 pessoal é político}

Embora de uso recente nas ciências sociais, o termo "empoderar" e seus correlatos remetem ao inglês "to empower", utilizado desde meados do século XVII com o 
sentido jurídico de "autorizar, investir de autoridade" e, mais tarde, derivando para o sentido de "habilitar ou permitir" (McLaughlin, 2016, p. 2). A partir da década de 1980, seu uso foi inspirado pelo legado dos movimentos sociais e políticos dos anos 1960 e 1970, a exemplo dos grupos de libertação de mulheres, do movimento Black Power e da Pedagogia do Oprimido formulada por Paulo Freire. O que essas abordagens têm em comum é a negação da ideia, contida no sentido original do termo, de que o poder pode ser simplesmente concedido ou autorizado a um indivíduo. Tal ideia é substituída pela tese de que o poder deve ser conquistado - não apenas individualmente, mas a partir da ação coletiva voltada à transformação estrutural. Ao mesmo tempo que acentuavam essa dimensão coletiva, tais correntes sustentavam que, se a dominação se imiscui nos domínios mais íntimos da existência social, a luta contra os seus mecanismos opressivos teria de ser desempenhada também nesses domínios.

Embora ainda não fizessem referência ao termo "empoderar", uma das contribuições mais significativas do feminismo radical para o desenvolvimento do conceito está encapsulada no famoso slogan "o pessoal é político". O registro da presença do "político" no domínio do "pessoal" pressupõe que as lutas de poder e as relações de dominação não existem somente no âmbito da "política" como esfera institucional, mas atravessam o conjunto da sociedade, incluindo-se aí as arenas privadas da vida familiar e das relações erótico-afetivas.

Como instrumento de uma agenda empoderadora, emancipatória, contudo, a ideia de que "o pessoal é político" não reduz uma política da transformação do mundo social a uma ética da autotransformação. Um dos elementos centrais dessa agenda estava associada aos chamados "grupos de conscientização" para gerar uma compreensão das diversas formas de opressão a que as pessoas estão submetidas "enquanto negras, trabalhadoras, inquilinas, consumidoras, crianças e também mulheres” (Sarachild, 1970, p. 80). 
Assim, embora a tomada de consciência fosse o elemento central dos grupos de conscientização de mulheres, diversas autoras enfatizavam que esses grupos não eram "terapêuticos", no sentido de voltados a transformações individuais desconectadas de transformações sociopolíticas: "problemas pessoais são problemas políticos. Não há soluções pessoais no momento. Existe apenas a ação coletiva para uma solução coletiva" (Hanisch, 1970, p. 77). De fato, pensar a libertação feminina em termos terapêuticos era amplamente considerado uma forma de sucumbir a uma "falsa consciência" segundo a qual as mulheres poderiam passar ao largo do combate político às estruturas sociais de sua opressão e "encontrar soluções individuais para os problemas, já que essa é a função da terapia” (Peslikis, 1970, p. 81).

Concepção semelhante aparece nos trabalhos de Paulo Freire, que, diferentemente das feministas radicais, já utiliza o termo "empoderamento", embora com ressalvas, em mea178 dos dos anos $1980^{5}$. Para o autor, o termo não faz sentido se utilizado como "autoempoderamento pessoal”: "eu não acredito em autolibertação. A libertação é um ato social” (Freire e Shor, 1987, p. 109). Isso porque, para Freire, a conscientização não é uma condição suficiente para a libertação. Nos termos de Guareshi (2010, p. 147):

Empoderamento é [...] para Freire um processo que emerge das interações sociais em que nós, seres humanos, somos construídos e, à medida que criticamente problematizamos a realidade, vamos nos "conscientizando", descobrindo brechas e ideologias; tal conscientização nos dá "poder" para transformar as relações sociais de dominação, poder esse que leva à liberdade e à libertação.

\footnotetext{
5 Salvo engano, o próprio Freire só faz uso do termo na década de 1980, mas em alguns países, como é o caso do Canadá, seu conceito de "conscientização", contido em obras das décadas de 1960 e 1970, foi traduzido como empowerment (Guareshi, 2010, p. 147).
} 
A partir da década de 1980, autoras ligadas ao feminismo negro, como Angela Davis, bell hooks e Patricia Hill Collins, também adotam explicitamente o termo "empoderamento", embora sem maiores preocupações com sua definição. Davis, por exemplo, ao afirmar que a noção de empoderamento já está presente na luta de mulheres afroamericanas desde a primeira onda, defende que suas estratégias mais eficientes de empoderamento se baseiem no slogan da Associação Nacional de Clubes de Mulheres de Cor do final do século XIX: "Lifting as we climb" ("levantando enquanto subimos"), i.e., "devemos subir de tal forma a garantir que todas as nossas irmãs, independentemente de classe social, de fato, todos os nossos irmãos, subam conosco. Esta deve ser a dinâmica essencial de nossa busca pelo poder" (Davis, 1988, p. 349). O empoderamento de mulheres negras depende, portanto, de um ativismo político que leve em consideração as associações íntimas entre racismo, classismo e sexismo - o que aponta, mais uma vez, para a dimensão estrutural do problema e suas soluções coletivas. Já Hill Collins (1990, p. xi-xii) caracteriza sua "política de empoderamento" em termos da necessidade de encontrar sua própria voz, uma que substitua "as definições externas de minha vida, veiculadas por grupos dominantes, pela minha própria perspectiva, autodefinida". Como nos casos precedentes, Collins não estava preocupada com uma voz meramente subjetiva, mas "individual e coletiva, pessoal e política, que reflita a interseção entre minha biografia única com o significado mais amplo de meu tempo histórico" (Hill Collins, 1990, p. xii). Inspirada em autores como Paulo Freire e Frantz Fanon, a autora defende ainda um processo de conscientização que coloque em evidência a supressão do conhecimento produzido por grupos subordinados, um processo que leva à internalização, por parte desses mesmos grupos, das ideologias dominantes. 
O que qualificamos acima como uma pauta coletivista de ação política revela que as primeiras formulações da noção de empoderamento se baseavam em uma linguagem identitária e continham um componente político radical. Em que pese a importância analítica e ético-política da ênfase no caráter composto das opressões e em hierarquias de poder cada vez mais complexas, a consciência da "interseccionalidade", no dizer de Kimberle Crenshaw (1989), levou a um impasse de difícil manejo: uma lógica de decomposição de categorias sociais em um número cada vez maior de subgrupos - por exemplo, das mulheres às mulheres negras, das mulheres negras às mulheres negras lésbicas etc. Nesse sentido, a despeito das aspirações emancipatórias que animaram o conceito de empoderamento, aquilo que James Heartfield chamou de "o etcetera sem fim da diferença" acabou operando como um instrumento de dissolução de alianças coletivas, contribuindo para a subs180 tituição da ideia de um sujeito político robusto, capaz de alterar a si mesmo e à sociedade, por identidades frágeis, vulneráveis e voltadas para si mesmas, o que altera a face de uma parcela importante do ativismo político contemporâneo (McLaughlin, 2016). Não obstante, ainda que essa seja uma das fontes da profunda transformação por que passou o conceito de empoderamento nas últimas décadas, as raízes históricas de tal transformação, como veremos, são muito mais complexas e multifacetadas.

\section{0 político é pessoal}

As transformações estruturais que atravessaram a(s) sociedade(s) capitalista(s) nos últimos cinquenta anos foram analisadas pela sociologia sob a égide de uma pluralidade de rótulos, como "modernidade tardia" (Giddens), "segunda modernidade" (Beck), "modernidade líquida" (Bauman) e "pós-modernidade" (Lyotard), dentre vários outros (Vandenberghe, 2013, p. 246). Tais diferenças 
terminológicas revelam, sem dúvida, discordâncias importantes nos retratos sociológicos atrelados a esses rótulos. Ao mesmo tempo, os mais diversos "diagnósticos de época" dirigidos à fase contemporânea da modernidade convergem no registro de uma série de tendências sócio-históricas, tais como a passagem de um regime econômico fordista para um regime de "acumulação flexível" (Harvey, 1990, p. 141), a flexibilização das relações de trabalho, a crise do estado de bem-estar social e a pluralização das formas de vida familiar. Autores como Bauman, Beck e Giddens também concordam quanto ao fato de que a operação conjunta dessas transformações leva a uma "sociedade individualizada" (Bauman, 2001) na qual os indivíduos são crescentemente impelidos, pela força de suas circunstâncias, a encontrar soluções biográficas para problemas sistêmicos (Beck, 1992, p. 137).

Segundo o argumento que Bauman desenvolve em diversas publicações (e.g., 2000), a fase "líquida" da modernidade introduz uma profunda disjunção entre trajetórias biográficas desenhadas a partir de escolhas pessoais e o ordenamento sistêmico de sociedades inteiras. Por um lado, devido aos processos de liberalização, flexibilização e "fluidificação" que afetam tantos domínios da existência individual (da trajetória profissional ao cuidado com o próprio corpo; da alimentação aos relacionamentos erótico-afetivos), os indivíduos não são apenas imbuídos da "oportunidade" de tornar seus percursos biográficos um projeto reflexivo; eles são obrigados a fazê-lo e em circunstâncias de significativa incerteza quanto ao seu sucesso ou fracasso. Por outro lado, a liberdade de iniciativa que os habitantes do mundo líquido-moderno encontram nas trajetórias individuais não se traduz em projetos coletivos de transformação da ordem social como tal. Ainda que os indivíduos tenham de responder de modo reflexivo e inventivo aos desafios que a modernidade líquida lhes impõe, eles respondem àqueles desafios como indivíduos e não como "cidadãos". Em outras 
palavras, as condutas desses agentes não se articulam em projetos coletivos de transformação das condições econômicas e políticas mais amplas nas quais estão imersos. Nos termos de Aristóteles, a busca da "boa vida" tornou-se desconectada da procura pela "Cidade justa".

A "individualização" crescente das respostas a problemas sistêmicos na modernidade tardia, com o correlato esvaziamento da dimensão política de tais respostas, pode ser observada em uma série de domínios, como as condições de trabalho ou o acesso a serviços de saúde. Seguindo a pista de autoras como Nancy Fraser (2013) e Cecília Sardenberg (2008), gostaríamos de explorar o modo pelo qual essa individualização despolitizante afetou os impactos e as apropriações de pautas feministas na sociedade moderno-tardia. Em particular, importa enfatizar que, à medida que o conceito de empoderamento foi apropriado por organizações e governos, terminou por legitimar práticas que, de uma 182 perspectiva feminista, estão longe de empoderar mulheres (Sardenberg, 2008, p. 18). Autoras como Angela McRobbie (2009) chegam mesmo a argumentar que, contemporaneamente, determinadas concepções de liberdade, empoderamento e escolha têm sido oferecidas às mulheres como uma espécie de substituto à política e transformação feminista.

A tese de que o capitalismo é capaz de integrar ao próprio funcionamento ideias e práticas que, de início, lhe são opostas ganha concretude histórica na análise de Boltanski e Chiapello sobre o que denominam $O$ novo espírito do capitalismo (2007). Nessa obra os autores conectam as transformações estruturais do capitalismo à inter-relação dinâmica entre suas ideologias de autojustificação e as críticas de que o sistema foi objeto. Nesse sentido, por exemplo, o rearranjo do capitalismo em linhas fordistas e keynesianas a partir dos anos 1930 pode ser lido, em parte, como resultado da incorporação da "crítica social” (Boltanski e Chiapello, 2007, p. 38) dirigida ao capitalismo liberal desde os seus 
primórdios. Como é sabido, a crítica social do capitalismo ataca o sistema como produtor de desigualdades distributivas e da exploração de uma maioria pobre por uma minoria rica. Se os mecanismos de proteção social próprios ao estado de bem-estar mitigaram parcialmente a "crítica social", o capitalismo estatalmente organizado foi contundentemente atacado por outra modalidade de anticapitalismo: a "crítica artística". Tal crítica fustigou as megaestruturas da economia industrial e da burocracia estatal como sufocadoras da autenticidade, da criatividade e da espontaneidade dos indivíduos. Com base em uma análise da literatura gerencial produzida entre as décadas de 1960 e 1990, Boltanski e Chiapello concluem que a reestruturação neoliberal do capitalismo a partir dos anos 1970 e 1980 se inspirou nos temas ventilados pela própria crítica artística. O desmantelamento dos mecanismos regulatórios do "capitalismo organizado" passou a valer-se, assim, de uma apropriação particular das demandas de outrora por espontaneidade, autonomia, flexibilidade e criatividade nos domínios da economia e do trabalho. Boltanski e Chiapello não têm muito a dizer a respeito de como as relações de gênero estiveram implicadas em tais mutações estruturais do capitalismo, mas o contorno geral de seu argumento se aplica a uma reflexão recente de Nancy Fraser (2013) sobre o destino socioideológico do feminismo da segunda onda.

Tal como Boltanski e Chiapello notam em relação à crítica artística, Fraser observa que as críticas do feminismo da segunda onda ao capitalismo keynesiano e fordista terminaram por alimentar sua reconfiguração neoliberal, flexível e individualizante a partir dos anos 1970. Nas suas fontes ativistas no feminismo da segunda onda, os ideais de ampliação da autonomia individual e do poder de escolha das mulheres nas mais diversas esferas (reprodução, família, trabalho, sexualidade etc.) caminhavam a par e passo com projetos de incremento na solidariedade social e na democracia 
participativa. No novo capitalismo, em contraste, a apropriação ideológica das demandas feministas por liberdade e iniciativa individual se fez, em larga medida, à custa daqueles ideais. Em primeiro lugar, o capitalismo organizado tinha no arranjo familiar "marido provedor, esposa dona de casa" um de seus sustentáculos, criticado pelas feministas como fonte e justificativa material da opressão das mulheres na esfera doméstica. Se a entrada maciça das mulheres no mercado de trabalho serviu para desestabilizar parcialmente aquele pilar de opressão, a mesma narrativa do empoderamento feminino, diz Fraser (2013), tem sido mobilizada para justificar regimes de trabalho que são eles próprios opressivos:

níveis salariais reduzidos, segurança no trabalho diminuída, padrões de vida declinantes, aumento precipitado no número de horas de trabalho por domicílio, exacerbação da jornada dupla - agora, frequentemente uma jornada tripla ou quádrupla - e aumento da pobreza, crescentemente concentrada em domicílios chefiados por mulheres.

De acordo com Fraser, o segundo ingrediente da agenda feminista incorporado ao ethos neoliberal conecta-se à relação entre reconhecimento e redistribuição, tema que desencadeou o debate altamente publicizado da autora com Axel Honneth (Fraser; Honneth, 2003). Contra um olhar restritivo sobre a luta pela emancipação, o qual não ia muito além de desigualdades econômicas, o feminismo da segunda onda jogou luz sobre uma série de opressões irredutíveis à economia, tais como estigmas culturais acerca da feminilidade que produzem, por si só, sofrimentos psíquicos para as mulheres. $\mathrm{Na}$ era do capitalismo desorganizado, entretanto, o desequilíbrio entre as agendas da redistribuição econômica e do reconhecimento cultural se inverteu. Segundo Fraser, a crítica a manifestações culturais sexistas terminou por eclipsar demandas por igualdade distributiva, justamente num 
período em que a "flexibilização" do capitalismo tende a acirrar desigualdades socioeconômicas em diversos países do mundo. Por fim, e de modo articulado, os ataques do feminismo da segunda onda aos componentes paternalistas do estado de bem-estar social, ataques originalmente pensados como parte de uma estratégia para o empoderamento dos cidadãos e uma partilha mais democrática do poder político, foram instrumentalizados na dissolução neoliberal do "estado-babá”. Como exemplo dessa tendência, Fraser menciona a crescente substituição de macroprogramas (inter) governamentais de combate à pobreza por estratégias paliativas e individualizantes como os chamados "microcréditos" - pequenos empréstimos bancários a mulheres pobres do Terceiro Mundo. Sendo mais um pacote de "soluções" individuais para problemas sistêmicos, tais iniciativas particularizam a ideia de empoderamento, desligando-a de qualquer agenda macropolítica que busque combater as raízes estruturais da pobreza e da desigualdade. Não é fortuito o uso de termos como "zonas de empoderamento" para designar programas que, na realidade, dizem respeito à privatização dos serviços públicos (McLaughlin, 2016).

Foi dessa dimensão individualizante das pautas feministas que os discursos midiáticos se apropriaram, em particular a publicidade. De acordo com Rosalind Gill e Christina Scharff (2011, p. 4), esses discursos refletem uma espécie de sensibilidade cultural (associada ao pós-feminismo) com as seguintes características:

a feminilidade é cada vez mais pensada como uma propriedade corporal; uma mudança da objetificação para subjetivação na forma como (algumas) mulheres são representadas; uma ênfase na autovigilância, no automonitoramento e na disciplina; um foco no individualismo, na escolha e no empoderamento; a dominância do paradigma da transformação [estética e 
cosmética]; um ressurgimento das ideias de diferença sexual natural; uma marcada ressexualização dos corpos das mulheres; uma ênfase no consumismo e na mercantilização da diferença.

Não por acaso, a beleza, que foi frequentemente denunciada como um mecanismo de sujeição feminina pelo feminismo de segunda onda, tem sido ressignificada como "direito" das mulheres (e.g., no título de um dos livros do cirurgião plástico Ivo Pitanguy, Direito à Beleza); em termos meritocráticos ("porque eu mereço", diz a propaganda da Elseve, da L'Oréal); como sustentáculo da autoconfiança ("tudo pode acabar, menos sua autoconfiança", ensina a campanha "Acredite na beleza”, de O Boticário). Não se trata, portanto, de mera estetização de motifs feministas, como afirma Goldman (1992), mas da introdução de valores relativos a um ethos neoliberal que, dentre outros elementos, fundamenta-se em uma concepção 186 de sujeito em termos de autogoverno, autonomia, empreendedorismo e performance (cf. Ehrenberg, 2010). É nesse sentido que a "individualização" das pautas do movimento feminista promove a transformação de objetivos sociopolíticos em escolhas individuais de estilo de vida, desarmando parte importante de seu aspecto político.

Como já afirmamos, manter uma postura crítica em relação à apropriação publicitária de pautas feministas não significa negar a existência de qualquer potencial ou componente "emancipatório" nessas propagandas. Ainda que por motivos meramente comerciais, não se pode negar que a publicidade tem absorvido grande parte da crítica à representação de mulheres em termos objetificantes, e isso tem consequências para o processo de socialização de crianças e mesmo de adultos ${ }^{6}$. Em compasso com o que Vandenberghe

\footnotetext{
${ }^{6}$ A importância da dimensão socializadora da publicidade é enfatizada por autoras como Susan Bordo (1999). Em sua análise do efeito de imagens da mídia em concepções de beleza e de normalidade, a autora menciona, por exemplo, um
} 
chama de teoria crítica "multidimensional" (2009) acreditamos que é possível articular, em um mesmo registro, o diagnóstico crítico da reprodução de formas de dominação com a identificação de aspectos emancipatórios nas configurações sociais contemporâneas.

De forma a ilustrar os argumentos desenvolvidos acima efetuaremos agora uma espécie de descrição densa do vídeo "Como uma garota", que inaugurou a campanha pelo empoderamento de meninas da marca de absorventes Always. Ao basearmos nossa descrição em dois trabalhos centrais ao feminismo de segunda onda, nosso propósito é evidenciar como é possível se apropriar ideologicamente de demandas feministas por liberdade e iniciativa individual em detrimento de ideais associados ao incremento da solidariedade social e da participação política. Em outros termos, trata-se de evidenciar a individualização e despolitização das pautas do feminismo de segunda onda no "feminismo da mercadoria".

\section{"Como uma garota": breve estudo de caso}

De acordo com um estudo de mercado desenvolvido pela D\&AD 7 o objetivo da campanha "Como uma garota" era apelar para uma nova geração de consumidoras. $\mathrm{Na}$ visão do estudo, enquanto a Always continuava enfatizando a performance do produto, a competição vinha adotando outras estratégias, como o engajamento emocional dos consumidores e o uso das mídias sociais. Nesse sentido, a marca demandou das agências publicitárias o desenvolvimento de uma campanha que acentuasse seu apoio ao empoderamento de meninas, um compromisso que supostamente

estudo em que meninos e meninas de onze anos foram solicitados a classificar uma série de desenhos que retratavam crianças com diversos tipos de "deficiência". Surpreendentemente, os desenhos de crianças gordas geraram mais desconforto e desaprovação do que os de crianças sem mãos ou com desfiguramento facial.

7 "Always: \#LikeAGirl". Disponível em: <https://digitalcasestudies.wordpress. com/2015/03/11/always-likeagirl-2/>. Acesso em: 27 fev. 2018. 
caracterizaria a marca há várias décadas, mas que as velhas estratégias publicitárias não deixavam evidente. Fazia-se necessário, então, "compreender os problemas enfrentados atualmente por meninas na puberdade".

Com base nisso, encomendou-se em 2014 uma enquete nacional nos EUA, que compreendeu uma amostra de 1300 jovens mulheres, entre 16 e 24 anos, sendo 150 afroamericanas e 150 latinas ("de origem hispânica") ("new social experiment”). Os principais resultados da pesquisa foram publicados no site oficial da Procter \& Gamble e sugerem que a enquete foi construída com base em duas categorias centrais: autoconfiança e feminilidade (cujo indicador principal diz respeito aos significados associados à expressão "como uma garota") ${ }^{9}$. Cerca de $56 \%$ das entrevistadas afirmaram ter experimentado uma queda na autoconfiança durante a puberdade, particularmente no período da primeira menstruação e no início do ensino 188 médio. As maiores taxas de queda da autoconfiança foram reportadas por meninas de origem hispânica (60\%), seguidas por caucasianas (sem dados) e por afrodescendentes $(50 \%)$. No que diz respeito ao significado de "como uma garota", a maioria das entrevistadas $(89 \%)$ concordou que as palavras podem machucar, especialmente as meninas. Apenas $19 \%$ associaram a expressão com algo positivo; $57 \%$ concordaram com a afirmação de que deveria haver algum tipo de movimento para mudar a percepção negativa associada a ela; e $81 \%$ afirmaram apoiar a iniciativa da Always para a criação de tal movimento.

\footnotetext{
8 Disponível em: <https://digitalcasestudies.wordpress.com/2015/03/11/ always-likeagirl-2/>.

${ }^{9}$ Dado que a descrição da metodologia se resume à especificação do tamanho da amostra, não temos como avaliá-la do ponto de vista de sua validade. No entanto, os resultados obtidos são compatíveis com a tese de Gilligan (1993) de que meninas experimentam uma queda na autoconfiança em torno da puberdade.
} 
O movimento assumiu a forma de uma série de "experimentos sociais", captados sob a forma de "documentários". O primeiro vídeo da série ${ }^{10}$, datado de 2014, tinha pouco mais de três minutos e foi posteriormente editado para ser exibido na abertura do Super Bowl. Ambas as versões foram amplamente divulgadas no Youtube e compartilhadas nas redes sociais. Na abertura da versão longa do vídeo, o tema do "documentário" é ancorado por meio da seguinte legenda: “o que significa fazer algo "como uma garota'?”. Na sequência solicita-se, individualmente, que jovens adultos (em torno dos vinte anos) e um menino desempenhem uma série de ações (correr, lutar, arremessar). O resultado revela-se na forma de movimentos corporais estereotipados e fracos: uma corrida interrompida por um "ai, meu cabelo", tapas desferidos com os braços tão próximos ao próprio corpo que não chegam a alcançar o alvo, um objeto arremessado com tão pouca força que cai perto demais dos próprios pés de quem arremessa, gerando um "ah" de frustração.

Ainda que isso não seja mencionado nos estudos que informam a campanha publicitária da Always, os movimentos estereotipicamente associados à expressão "como uma garota” foram objeto de uma análise detalhada feita pela filósofa Iris Marion Young (2005) em um ensaio originalmente publicado no início da década de 1980. Com base em articulação criativa entre as fenomenologias existenciais de Simone de Beauvoir e Maurice Merleau-Ponty, Young descreve três características centrais nos modos como as mulheres na modernidade ocidental conduzem seus corpos: "transcendência ambígua", "intencionalidade inibida" e "unidade descontínua" consigo e com o ambiente circundante (2005, p. 35). Ela parte do exemplo do "lançar como uma garota": quando uma garota arremessa uma bola, ela não engaja seu corpo

${ }_{10}$ Disponível em: <https://www.youtube.com/watch?v=lM6hSM29HTc > Acesso em: 25 abr. 2017. 
inteiro no movimento. Em vez do giro para trás seguido da projeção para a frente, típicos dos meninos, as meninas utilizariam somente o antebraço (2005, p. 27). Segundo Young, o mesmo padrão seria encontrado em outros movimentos de meninas, como no correr, no escalar, no sentar e no socar: as meninas não mobilizam o corpo como um todo em favor de um movimento otimamente expansivo, mas confinam seu movimento a uma parte do corpo, contendo sua própria expansão no espaço - o que é expresso de forma estereotipada na primeira parte do vídeo da Always.

Tal estilo de se movimentar seria signo de um ser-no-mundo marcado pela timidez e pela hesitação, bem como por uma experiência do corpo menos como um instrumento prático de efusão ativa de si sobre o mundo do que como um objeto vulnerável que necessita de proteção. A expansividade parcial e autocontida desses movimentos expressaria uma ambivalência constitutiva da existência feminina no Ocidente moderno. Ainda que os propósitos do ensaio de Young sejam eminentemente descritivos, ela obviamente não atribui essa ambivalência a fatores naturais ou a qualquer espécie de "essência" da mulher, mas sublinha com vigor as fontes histórico-culturais de tais modos "femininos" de condução do próprio corpo.

O que Merleau-Ponty chamou de "transcendência" do ser humano em relação ao mundo consiste na capacidade de se projetar ativamente no ambiente circundante e nele produzir efeitos. Segundo a "fenomenologia gendrada" de Young, a "ambiguidade" dessa transcendência nos movimentos corporais de mulheres deriva do grau em que a efusão ativa do próprio corpo sobre o mundo permanece, entre elas, emperrada, hesitante, tímida e autocontida. Nos seus movimentos, o corpo é exteriormente visto e internamente experimentado menos como "sujeito expansivo" capaz de produzir efeitos no mundo e mais como um "objeto vulnerável”, que não deve ser forçado aos seus limites e precisa ser abrigado de riscos 
externos. Um exemplo disso é a auto-objetificação envolvida no comentário "ai, meu cabelo!", feito por uma mulher adulta correndo "como uma garota" no início da propaganda.

Essa referência ao próprio cabelo permite conectar a propaganda a um dos momentos em que Young vai além da descrição fenomenológica e oferece pistas para explicar por que "a existência corporal feminina é uma intencionalidade inibida que, simultaneamente, busca um fim projetado com um 'eu posso' e contém seu compromisso corporal pleno com um ‘eu não posso' autoimposto” (2005, p. 36). A concepção do próprio corpo como objeto, mais do que como sujeito, não deriva apenas do fato de que mulheres são ensinadas a subestimarem suas forças físicas, mas também do grau em que o juízo social sobre seus corpos se concentra muito mais em sua aparência do que em suas capacidades. Não precisamos ir muito longe na interpretação para concluirmos que o "ai, meu cabelo!" não exprime vulnerabilidade à dor, mas a preocupação com a "desarrumação". Para Young, com efeito, quando a monitoração externa da aparência física é interiorizada via socialização, os movimentos corporais são sempre contidos por uma automonitoração dirigida à aparência como objeto. A autorreferência corpórea explica também o último atributo listado por Young: a "unidade descontínua" consigo e com o ambiente. A efusão intencional plena do corpo sobre o mundo supõe que o corpo todo seja vivido como sujeito. A vivência de si como objeto condena parte do corpo a permanecer imóvel, isto é, a não contribuir com o movimento tencionado (p. ex., somente o braço lança a bola, enquanto as pernas permanecem fincadas no chão). Além disso, enquanto a projeção intencional de si no mundo envolve um senso de apropriação ativa (no caso do vôlei citado por Young, ir à bola como um objeto da minha força), a percepção de si como objeto entre objetos leva à passividade ou a meros movimentos de proteção (p. ex., defender o rosto diante da bola que vem com velocidade na minha direção). 
O texto de Young cinge-se à descrição das formas típicas de movimento entre as mulheres ocidentais, sem oferecer um programa para uma reconfiguração eticamente motivada da condução do próprio corpo pelas mulheres. Com efeito, em momento posterior de sua carreira, a própria autora atacou o ensaio por supostamente mostrar as mulheres apenas em termos de vulnerabilidade e tomar implicitamente os estilos masculinos de movimento como padrão normativo (Bartky, 2009, p. 49-51). Em uma defesa de Young contra a própria Young, Bartky sustenta, contudo, que uma teoria crítica voltada a práticas emancipatórias poderia tomar como pontos de partida suas investigações detalhadas dos efeitos da dominação masculina sobre o ser-no-mundo corpóreo das subjetividades gendradas como "femininas". Em um segundo momento, no entanto, a crítica deveria partir dessas investigações para descortinar caminhos de transformação dos hábitos corporais que cons192 tituem a interiorização da dominação de gênero. A agenda feminista conectar-se-ia, nesse sentido, a uma espécie de reeducação corporal emancipatória voltada, por exemplo, a tornar "inambígua" a transcendência do corpo e a "desinibir" sua intencionalidade, para usar o vocabulário fenomenológico-existencial de Young.

Essa ressignificação dos movimentos corporais comumente associados à expressão "como uma garota" é o objetivo autodeclarado da propaganda da Always. Nesse sentido, poder-se-ia dizer que a propaganda possui um componente emancipatório, no sentido de uma reconfiguração da condução da própria corporeidade - reconfiguração que envolveria, por exemplo, tomar o próprio corpo como um "sujeito" que se projeta no mundo (em vez de um "objeto" vulnerável) ou realizar movimentos plenamente expansivos (em vez de parciais e autocontidos) e assim por diante. Já afirmamos que é possível fazer tal apreciação normativa da propaganda sem deixar de contrabalançá-la com considerações acerca 
da força "canibalizadora" do capitalismo atual e da individualização crescente de pautas políticas ao longo das linhas desenhadas pelo ethos neoliberal (autonomia, iniciativa, empreendedorismo, culto da performance etc.).

Tais considerações se tornam mais inteligíveis no restante do vídeo, agora buscando ressonâncias com outro clássico da literatura feminista: o trabalho de Carol Gilligan sobre o desenvolvimento de meninas (Gilligan, 1993 [1982] e 1990; Gilligan e Brown, 1992)

Vimos anteriormente que, em resposta à pergunta "o que significa fazer algo 'como uma garota'?”, adultos da faixa de vinte anos, além de um menino mais novo, realizaram movimentos caricaturalmente fracos e inibidos, ao estilo daqueles que foram tão bem analisados por Young. Em seguida a essa cena, o vídeo traz uma nova legenda: "Pedimos a mesma coisa a meninas jovens". Em contraste com os adultos, as meninas executam seus movimentos de modo vigoroso e confiante, sem quaisquer afetações de ineficiência e frustração. Logo depois, o significado da expressão, antes representado por movimentos corporais, é solicitado pela diretora do documentário em termos verbais: "o que significa para você quando eu digo 'corra como uma garota'?". "Significa 'corra o mais rápido que puder'”, afirma a menina que aparenta cerca de seis anos de idade. Nova legenda, numa clara alusão ao desenvolvimento infantil: "quando foi que fazer algo 'como uma garota' tornou-se um insulto?". Agora, a diretora estabelece um breve diálogo com o único menino (aparentando cerca de dez anos) a figurar no vídeo: "Então, você acha que acaba de insultar sua irmã?”. "Não!”, ele responde de forma enfática, e se contradiz, constrangido, mas reticente: "quer dizer, sim... eu insultei meninas, mas não minha irmã”. E voltando-se a uma das meninas, que aparenta a mesma idade do menino, a diretora pergunta: "[A expressão] 'como uma garota' é algo bom?". "Na verdade eu não sei se é uma coisa boa ou 
ruim", hesita a menina, sem perder a assertividade, "soa como se você tivesse querendo humilhar alguém". A mistura de dúvida e autoconfiança é então contrastada com uma nova legenda: "a autoconfiança de uma menina despenca na puberdade" e "a Always quer mudar isso". O foco num discurso verbal, possivelmente numa tentativa de melhor ancorar a mensagem pretendida, continua nas perguntas dirigidas às jovens mulheres que apareceram anteriormente: "Quando estão em sua fase mais vulnerável, entre os 10 e os 12 anos, você acha que isso afeta [as meninas] quando alguém diz 'como uma garota' como um insulto?". "Eu acho que isso definitivamente abaixa sua autoconfiança e realmente as coloca para baixo, porque durante esse período elas estão tentando descobrir quem são, e quando alguém diz 'você rebate como uma garota', é como se dissesse ... que elas são fracas e que não são tão boas quanto os outros".

Embora a queda na autoconfiança de meninas durante 194 a puberdade não constituísse o foco inicial do trabalho de Gilligan, o fenômeno foi por ela observado em uma série de trabalhos empíricos relativos ao desenvolvimento moral. Seu livro Em uma voz diferente, originalmente publicado em 1982, consistiu em uma crítica a teóricos do desenvolvimento infantil, particularmente a seu ex-orientador Lawrence Kohlberg, que argumentou que as mulheres não atingiam o que ele concebia como o último estágio de desenvolvimento moral, o estágio 6 , baseado no uso de raciocínios abstratos relativos a princípios éticos universais e à ideia de justiça. Resumidamente, o argumento de Gilligan é o de que a definição do desenvolvimento moral em termos da evolução de selves autônomos, capazes de aplicar princípios abstratos universais, não dá conta do todo da experiência moral humana. Isso porque alguns problemas morais decorrem não da "competição entre direitos" que requerem um tipo de pensamento formal e abstrato, mas da "competição entre responsabilidades", o que requer um tipo de pensamento 
"narrativo e contextual". Mais especificamente, os dilemas morais identificados nos últimos estágios de desenvolvimento - caracterizados em termos de como definir fronteiras claras entre os indivíduos e protegê-los dos conflitos ou, em termos mais abstratos, de como exercer os próprios direitos sem interferir nos direitos dos outros - precisam ser expandidos a fim de incluir outro tipo de questão: o de como restaurar as fraturas que podem ocorrer nas relações humanas concretas e particulares de forma responsável (consigo e com os outros) (Gilligan, 1993 [1982], p. 21). Embora isso tenha sido frequentemente formulado em termos de uma relação (às vezes de oposição) entre uma ética da justiça e uma ética do cuidado, autoras como Susan Hekman (2014, pp. 56-76) e Susan Bordo (1999, pp. 204-207) apontam para uma consequência mais ampla dessas considerações: uma concepção alternativa de self, pensado não mais como sujeito autônomo e universal, mas como um sujeito relacional, formado por suas relações com outros e a partir de suas experiências (no caso, gendradas). Em acordo com outras teóricas das relações objetais, Gilligan explica a diferença a partir da forma como meninos e meninas são socializados: dado que, ao contrário dos meninos, as meninas não são encorajadas a se separarem de suas mães, elas tendem a "desenvolver habilidades relacionais" e a pensar a autonomia como "algo problemático"; já os meninos são socializados no sentido de temer as relações e desenvolver habilidades relativas à autonomia.

De acordo com Gilligan (1990), o encontro dessas lógicas distintas tende a se apresentar às meninas durante a adolescência, com consequências devastadoras para sua autoconfiança. Ao confrontar aquilo que a autora denomina de "o muro da cultura ocidental" (outro termo para a cultura patriarcal), meninas que aos onze ou doze anos se expressavam de maneira assertiva e autoconfiante passam a se apresentar de maneira conformista, hesitante e a 
opor menos resistência àquilo que consideram moralmente injusto:

quando trazido para o mundo público, o saber de meninas é frequentemente desconsiderado como trivial ou visto como transgressivo, com o resultado de que as meninas são reiteradamente instadas a não falar, a não dizer nada, ou pelo menos a não falarem em público sobre o que elas sabem (Gilligan, 1990, p. 520).

Em um sentido importante, o que as meninas aprendem na passagem da socialização primária para a secundária (e os meninos, ainda na socialização primária) é que ser "uma boa mulher" nas sociedades ocidentais é renunciar a seu próprio conhecimento sobre o corpo e sobre as relações, conformando-se à concepção dominante de sujeito: abstrato, racional, descorporificado, solipsista. Paradoxalmente, 196 aponta a autora (Brown e Gilligan, 1992, p. 217), essa renúncia ocorre como uma tentativa de manter as relações com os outros, mas agora sob a forma de evitação do conflito: o que antes era considerado pelas meninas como honestidade na resolução de conflitos interpessoais (p. ex., o ato de dizer abertamente o que pensa ou de intervir em favor de alguém com base em características específicas e particulares), passa a ser interpretado em termos de egoísmo, maldade, rudeza ou simplesmente estupidez. Haveria, assim, uma tendência, na passagem da infância para a adolescência, "de uma resistência que é essencialmente política" - uma insistência em saber o que se sabe e uma vontade de falar o que se pensa - "para uma resistência psicológica: uma relutância em se saber o que se sabe e um temor de que tal saber, se falado, colocará suas relações em risco e ameaçará sua sobrevivência” (Gilligan, 1990, p. 501).

Essa resistência psicológica, entendida no sentido de uma estratégia de sobrevivência diante de realidades 
relacionais incomensuráveis, é mais tarde retratada em termos de formas diversas de dissociação: entre a psique e o corpo, os sentimentos e os pensamentos, os pensamentos e a voz (Brown e Gilligan, 1992). Assim, se as reflexões iniciais de Gilligan sobre a relação entre resistência psicológica e resistência política visavam salvaguardar o potencial emancipatório da primeira (no sentido de que, mesmo sob o signo da repressão, aquilo que foi reprimido poderia um dia se tornar uma "resistência pública"), seu trabalho com Brown aponta para uma conclusão muito mais pessimista: a de que "o movimento em direção ao mar da cultura ocidental" é um "movimento de perda psicológica profunda" (1992, p. 180). Isso, por um lado, desautoriza qualquer tentativa de reduzir ou mesmo de fundamentar a resistência política na resistência psicológica; por outro, constitui uma forte crítica a concepções abstratas de self e de direitos. De fato, como sugere Bordo (1999), o que a diferença de gênero enfatizada por Gilligan proporciona é basicamente uma porta de entrada para uma crítica cultural - uma dimensão que não pode ser excluída quando consideramos a propaganda da Always. Contudo, há uma diferença significativa no ethos considerado: enquanto Gilligan enfatiza a existência de valores ligados às relações e uma concepção relacional de self, a publicidade enfatiza valores ligados à performance, ao sucesso individual e à autonomia - algo amplamente explorado por meio das metáforas esportivas.

O restante do "documentário", em que a diretora estabelece uma série de diálogos com as mulheres que figuraram na primeira parte do anúncio, fornece uma pista importante para o ethos que está em jogo. À pergunta da diretora "O que você aconselharia a meninas jovens quando elas ouvem que correm como uma garota, chutam como uma garota, nadam como uma garota?", a "entrevistada” responde: "Continue fazendo isso, porque está funcionando. Se alguém lhe disser que correr como uma garota ou chutar 
como uma garota ou atirar como uma garota é algo que você não deveria fazer, isso é problema deles. Porque se você ainda está marcando pontos, ainda está chegando na bola a tempo e ainda está chegando em primeiro lugar, você está fazendo a coisa de forma certa, não importa o que digam...”.

"Se eu lhe pedisse para correr como uma garota agora, você faria diferente?", pergunta a diretora a outra das mulheres que havia desempenhado as ações solicitadas no início. "Eu correria como eu mesma", responde a moça, sugerindo a recuperação imediata da autoconfiança e da autenticidade perdidas. "Você gostaria de tentar de novo?". A isso se segue uma série de imagens das mesmas mulheres que antes desempenharam os movimentos estereotipados - que agora se movimentam de forma fluida, ampla, eficiente - acompanhadas de novas legendas que enfatizam o nome da campanha e sua hashtag: "Vamos fazer \#comoumagarota significar coisas incríveis" e "junte-se a nós para promover a autoconfiança 198 de meninas na Always.com”. Por fim, o convite à ressignificação por parte de uma das jovens mulheres - "Por que 'correr como uma garota' também não pode significar 'vença a corrida'?" e a legenda: "reescreva as regras Always [sempre]" ${ }^{11}$.

Reescrever as regras, ao que tudo indica, depende simplesmente de seguir os "imperativos do self empreendedor" (Rose, 1996) a fim de vencer a corrida. Como argumentado ao longo deste trabalho, em lugar da crítica às estruturas de dominação, da importância dos laços sociais e das estratégias coletivas de luta política, enfatizam-se a autoconsciência, o autogoverno, a

\footnotetext{
11 Esses elementos são também enfatizados no segundo vídeo da campanha, sob o título de "unstoppable". Ao enfatizar que " $72 \%$ das meninas sentem que a sociedade as limita" e que "a Always quer mudar isso", meninas são solicitadas a escrever em grandes caixas de papelão as limitações a que elas se sentem submetidas. As principais: "sem valor", "fraca", "covarde", "feia", "meninas não podem jogar basquete", "bonita", "mandona", "submissa”, "pequena", "chorona”, "não pode ter músculos”. Essas caixas são depois atacadas pelas próprias meninas, em movimentos certeiros e fluidos, seguindo-se o convite a nos juntarmos à campanha para o aumento da autoconfiança de meninas. Disponível em: <https://www.youtube. com/watch?v=VhB311gCz2E $>$. Acesso em: 25 abr. 2016.
} 
eliminação da dependência, a competição, o sucesso individual e a liberdade para fazer escolhas. Revelam-se, assim, o alcance e os limites do empoderamento no feminismo da mercadoria.

\section{Cynthia Hamlin}

é Doutora em Pensamento Político e Social pela Universidade de Sussex (1997) e professora associada do Departamento de Sociologia da Universidade Federal de Pernambuco (UFPE), onde coordena o Grupo de Estudos em Teoria Social e Subjetividades (GETSS).

\section{Gabriel Peters}

é Doutor em Sociologia pelo Instituto de Estudos Sociais e Políticos da Universidade do Estado do Rio de Janeiro (IESPUERJ) e professor adjunto do Departamento de Sociologia da Universidade Federal de Pernambuco (UFPE). Colabora com o Grupo de Estudos em Teoria Social e Subjetividades (GETSS) na UFPE e com o Núcleo de Pesquisa em Filosofia das Ciências Sociais (Sociofilo) no IESP-UERJ.

\section{Bibliografia}

ARANHA, Jacob. 2014. Economic empowerment of dalit women. Nova Delhi: Shree.

BARRET, Michèle. 1992. Words and things: materialism and method in contemporary feminist analysis. In: BARRETT, Michèle; PHILLIPS, Anne. (eds.). Destabilizing theory: contemporary feminist debates. Cambridge: Polity. pp. 201-2019.

BARTKY, Sandra Lee. 2009. Iris Young and the gendering of phenomenology. In: FERGUSON, Ann; NAGEL, Mechthild. (eds.). Dancing with Iris: the philosophy of Iris Marion Young. Oxford:

Oxford University Press. p. 41-52.

BAUMAN, Zygmunt. 2000. Liquid modernity. Cambridge: Polity. 2001. The individualized society. Cambridge: Polity.

BECK, Ulrich. 1992. The risk society: towards a new modernity. London: Sage. BOLTANSKI, Luc; CHIAPELLO, Eve. 2007. The new spirit of capitalism.

London: Verso. 
BORDO, Susan. 1999. Twilight zones: the hidden life of cultural images from Plato to O.J. Berkeley: University of California Press.

BROWN, Lyn Mikel; GILLIGAN, Carol. 1992. Meeting at the crossroads: women's psychology and girl's development. Cambridge: Harvard University Press.

CASTELLS, Manuel. 1999. O poder da identidade. Tradução de Klaus Brandini Gerhardt. São Paulo: Paz e Terra.

CRENSHAW, Kimberle. 1989. Demarginalizing the intersection of race and sex: a black feminist critique of antidiscrimination doctrine, feminist theory and antiracist politics. University of Chicago Legal Forum, Chicago, v. 140, n. 1, pp. 139-167.

DAVIS, Angela. 1988. Radical perspectives on the empowerment of AfroAmerican women: lessons for the 1980s. Harvard Educational Review, Cambridge, MA, v. 58, n. 3, pp. 348-354. Sept. 1988.

EICHNER, Maxine. 2016. Market-cautious feminism. Studies in Law, Politics, and Society, Bingley, v. 69, Special Issue: Feminist Legal Theory, pp. 141-187.

EHRENBERG, Alain. 2010. O culto da performance: da aventura empreendedora à depressão nervosa. Tradução de Pedro Fernando 200 Bendassolli. São Paulo: Ideias \& Letras.

FRASER, Nancy. 1995. From redistribution to recognition? dilemmas of Justice in a 'post-socialist' age. New Left Review, London, v. 212, pp. 68-93. July-Aug. 1995.

2013. How feminism became capitalism's handmaiden and how to reclaim it. The Guardian, Opinion. London, 14 out. 2013. Disponível em: <https://goo.gl/n2PGZv>. Acesso em: 22 fev. 2018.

FRASER, Nancy.; HONNETH, Axel. 2003. Redistribution or recognition? A political-philosophical exchange. London: Verso.

FREIRE, Paulo; SHOR, Ira. 1987. A pedagogy for liberation: dialogues for transforming education. London: Macmillan.

GILL, Rosalind. 2008. Empowerment/sexism: figuring female sexual agency in contemporary advertising. Feminism \& Psychology, Thousand Oaks, CA, v. 18, n. 1, pp. 35-60. 21 jan. 2008.

GILL, Rosalind; SCHARFF, Christina. (eds.). 2011. New femininities: postfeminism, neoliberalism and subjectivity. London: Palgrave Macmillan.

GILLIGAN, Carol. 1990 [1982]. Joining the resistance: psychology, politics, girls and women. Michigan Quarterly Review, Ann Arbor, MI, v. 24 , n. 9 , pp. 501-36. 
1993 [1982]. In a different voice: psychological theory and women's development. Cambridge, MA: Harvard University Press.

GOLDMAN, Robert. 1992. Reading ads socially. Abingdon: Taylor \& France.

GUARESHI, Pedrinho. 2010. Empoderamento. In: STRECK, Danilo Romeu; REDIN, Euclides; ZITKOSKI, Jaime José. (orgs.). Dicionário Paulo Freire. Belo Horizonte: Autêntica. p. 147.

HANISCH, Carol. 1970. The personal is political. In: FIRESTONE, Suylamith; KOEDT, Anne. (eds.). Notes from the Second Year: Women's Liberation, major writings of the radical feminists. Nova York: Radical Feminism. pp. 76-77

HARVEY, David. 1990. The condition of postmodernity: an enquiry into the origins of cultural change. Oxford: Blackwell. 2005. A brief history of neoliberalism. Oxford: Oxford University Press.

HEKMAN, Susan. 2014. The feminine subject. Cambridge: Polity.

HILL COLLINS, Patricia. 1990. Black feminist thought: knowledge, consciousness and the politics of empowerment. London: Hyman.

JAMESON, Fredric. 1991. Postmodernism: or the cultural logic of late capitalism. Durham: Duke University Press.

MACLARAN, Pauline. 2015. Feminism's fourth wave: a research agenda for marketing and consumer research. Journal of Marketing Management, London, v. 31, n. 15-16, pp. 1732-1738.

MCLAUGHLIN, Kenneth. 2016. Empowerment: a critique. London: Routledge.

MCROBBIE, Angela. 2009. The aftermath of feminism: gender, culture and social change. London: Sage.

PESLIKIS, Irene. 1970. Resistances to consciousness. In: FIRESTONE, Sulamith; KOEDT, Anne. (eds.). Notes from the Second Year: Women's Liberation, major writings of the radical feminists. Nova York: Radical Feminism. p. 81.

ROCHA, Maria Eduarda. 2009. A nova retórica do capital: a publicidade brasileira em tempos neoliberais. São Paulo: Edusp.

ROSE, Nikolas. 1996. Inventing our selves: psychology, power and personhood. New York: CUP.

SARDENBERG, Cecília M. B. 2008. Liberal vs Liberating Empowerment: a Latin American feminist perspective on conceptualizing women's empowerment. IDS Bulletin, Brighton, v. 39 n. 6, pp. 18-27.

VANDENBERGHE, Frédéric. 2009. A philosophical history of German sociology. London: Routledge.

2013. What's critical about critical realism: essays in reconstructive social theory. London: Routledge. 
VEBLEN, Thorstein. 1987 [1899]. Teoria da classe ociosa: um estudo econômico das instituições. São Paulo: Nova Cultural.

SARACHILD, Kathie. 1970. A program for feminist "consciousness raising”. In: FIRESTONE, Sulamith; KOEDT, Anne. (eds.). Notes from the Second Year: Women's Liberation, major writings of the radical feminists. Nova York: Radical Feminism. p. 78-80.

STAMPLER, Laura. 2014. Here's how women respond to all those 'Female Empowerment' ads. Time Magazine, Amsterdam, 14 Oct. 2014. Disponível em: <https://goo.gl/SdX1g3>. Acesso em: 22 fev. 2018. WOMEN now empowered by everything a woman does. 2003. The Onion, Chicago, v. 43, n. 19. Disponível em: <https://goo.gl/RmKeTC>. Acesso em: 22 fev. 2018.

YOUNG, Iris Marion. 2005. Throwing like a girl: a phenomenology of feminine body comportment, motility, and spatiality. In: YOUNG, Iris Marion. On female body experience: "Throwing like a girl" and other essays. Oxford: Oxford University Press. pp. 27-45.

ZEISLER, Andi. 2016. We were feminists once: from riot grrrl to covergirl®, the buying and selling of a political movement. New York: Public Affairs.

ZOLA, Émile. 2008. [1883]. O paraíso das damas. São Paulo: Estação 


\section{CONSUMINDO COMO UMA GAROTA: SUBJETIVAÇÃO E EMPODERAMENTO NA PUBLICIDADE VOLTADA PARA MULHERES}

CYNTHIA HAMLIN

\section{GABRIEL PETERS}

Resumo: $\mathrm{O}$ artigo explora o uso de temas feministas na publicidade contemporânea, com ênfase na apropriação publicitária da noção de "empoderamento". A análise desse "feminismo da mercadoria" demonstra que, a despeito de potenciais aspectos emancipatórios, os usos publicitários do conceito de empoderamento revelam um sentido individualizante que se afina ideologicamente com o ethos do capitalismo tardio e com formas de subjetivação que enfatizam a autoconsciência, o autogoverno, a independência, o sucesso individual e a liberdade para fazer escolhas. Tal inflexão destoa dos compromissos coletivistas com transformações estruturais antes atrelados ao conceito pelo feminismo de segunda onda. Se o slogan feminista de que "o pessoal é político" vinculava a autotransformação individual à transformação social, a proposta de empoderamento veiculada no femvertising esvazia aqueles compromissos através da sugestão implícita de que "o político é pessoal". O artigo ilustra tais argumentos com o exame de uma campanha publicitária promovida pela marca de absorventes Always, enfatizando como a dimensão política do feminismo de segunda onda, presente em reflexões como as de Carol Gilligan e de Iris M. Young, pode ser apropriada de forma a compatibilizá-la ao ethos neoliberal e suas formas específicas de subjetivação.

Palavras-chave: Feminismo; Publicidade; Empoderamento; Subjetivação.

\section{CONSUMING LIKE A GIRL: SUBJECTIVATION AND EMPOWERMENT IN ADS TARGETING WOMEN}

Abstract: In this paper we explore the use of feminist themes in contemporary advertisement campaigns, emphasizing 
their appropriation of the notion of empowerment. The analysis of this "commodity feminism" shows that, despite its potential emancipatory aspects, the uses of the notion in advertisement reveal an individualizing meaning that is ideologically compatible with the ethos of late capitalism and with forms of subjectivation that emphasize selfconsciousness, self-government, independence, individual success, and freedom to choose. Such conception is at odds with the collective commitment to structural changes that characterized the notion of empowerment developed by second wave feminists. If the feminist slogan according to which "the personal is political" linked individual self-transformation to social transformation, the idea of empowerment advanced in femvertising negates that commitment to structural changes by implying that "the political is personal". We illustrate these arguments with the analysis of an advertising campaign developed by the brand Always. Here we show how the political dimension in theories of second wave feminists such as Carol Gilligan and Iris M. Young can be appropriated in a way that make their ideas compatible with a neoliberal ethos and their specific forms of subjectivation.

Keywords: Feminism; Advertising; Empowerment; Subjectivation.

Recebido: 01/06/2017

Aprovado: 28/07/2017 